Loma Linda University

TheScholarsRepository@LLU: Digital Archive of Research, Scholarship \& Creative Works

Loma Linda University Electronic Theses, Dissertations \& Projects

$5-1981$

\title{
The Effects of Maxillary Quad-Helix Appliance Expansion on Cephalometric Measurements in Growing Orthodontic Patients
}

Steven Wesley Frank

Follow this and additional works at: https://scholarsrepository.llu.edu/etd

Part of the Orthodontics and Orthodontology Commons

\section{Recommended Citation}

Frank, Steven Wesley, "The Effects of Maxillary Quad-Helix Appliance Expansion on Cephalometric Measurements in Growing Orthodontic Patients" (1981). Loma Linda University Electronic Theses, Dissertations \& Projects. 1332.

https://scholarsrepository.llu.edu/etd/1332

This Thesis is brought to you for free and open access by TheScholarsRepository@LLU: Digital Archive of Research, Scholarship \& Creative Works. It has been accepted for inclusion in Loma Linda University Electronic Theses, Dissertations \& Projects by an authorized administrator of TheScholarsRepository@LLU: Digital Archive of Research, Scholarship \& Creative Works. For more information, please contact scholarsrepository@llu.edu. 
Abstract

THE EFFECTS OF MAXILLARY QUAD-HELIX APPLIANCE EXPANSION ON CEPHALOMETRIC MEASUREMENTS IN GROWING ORTHODONTIC PATIENTS

by

Steven Wesley Frank

This study was conducted to examine the effects of maxillary quad-helix expansion on frontal and lateral cephalometric measurements in growing orthodontic patients. Twenty subjects, nine girls and eleven boys ( $\bar{x}$ age $=10$ years, 3 months), each exhibiting at least a unilateral posterior lingual cross-bite that had been treated with a maxillary quad-helix appliance, were selected for this study. Posterior-anterior and lateral cephalometric radiographs were taken at the beginning of treatment $\left(\mathrm{T}_{1}\right)$, when the appliance was removed ( $T$ prog, $\overline{\mathrm{x}}$ time $=$ nine months) and at retention $\left(\mathrm{T}_{2}\right)$ and subsequently traced. The $\mathrm{T}_{1}$ and $\mathrm{T}_{2}$ dental casts were also measured as a supplement to the cephalometric measurements. Significant orthodontic changes, as seen on the frontal radiographs from $\mathrm{T}_{1}$ to $\mathrm{T}_{\text {prog' }}$ included a mean increase in maxillary intermolar width of 5.88 $\mathrm{mm}$, a mean increase in average frontal molar relation of 
of $2.95 \mathrm{~mm}$ and a mean increase in maxillary intercanine width of $2.74 \mathrm{~mm}$. The orthopedic changes, as evidenced radiographically, included a mean increase in maxillary width of $.92 \mathrm{~mm}$ and an increase in average maxillomandibular width of $.89 \mathrm{~mm}$. From the above data a $6: 1$ ratio of orthodontic movement to orthopedic movement was determined. No significant change in mandibular intermolar width was observed from the cephalometric data or the cast measurements. The most stable cases after expansion presented with normal nasal widths and narrow maxillary widths. No correlation was shown between the age of the patients and the orthopedic expansion recorded, or the amount of orthodontic/orthopedic expansion and facial type. It was concluded that all expansion changes showed little relapse from $\mathrm{T}_{\text {prog }}$ to $\mathrm{T}_{2}$, and that moderate orthopedic expansion is possible with the quad-helix', but only slight orthopedic expansion was consistently demonstrated. 
LOMA IINDA UNIVERSITY

Graduate School

THE EFFECTS OF MAXILLARY QUAD-HEIIX APPLIANCE EXPANSION ON CEPHALONETRIC MEASUREMENTS IN GROWING ORTHODONTIC PATIENTS

A Manuscript Submitted by Steven Wesley Frank, in Partial Fulfillment of the Requirements for the Degree Master of Science in Orthodontics 
Each person whose signature appears below certifies that this manuscript in his opinion is adequate, in scope and quality, in lieu of a thesis for the degree Master of Science.
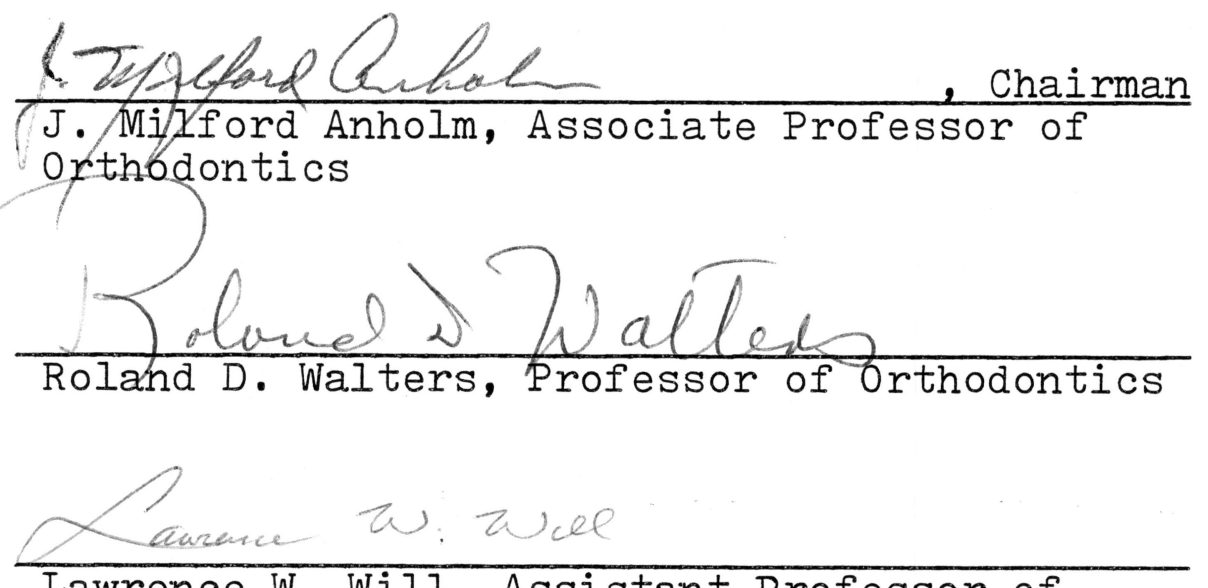

Lawrence W. Will, Assistant Professor of Orthodontics

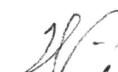

vilis tohlenter

Willis L. Schlenker, Assistant Professor of Orthodontics
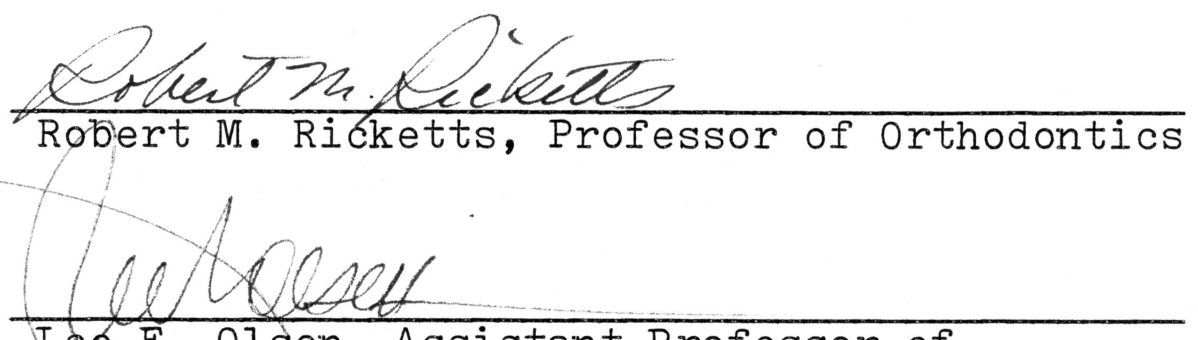

Lee E. Olsen, Assistant Professor of

Orthodontjes

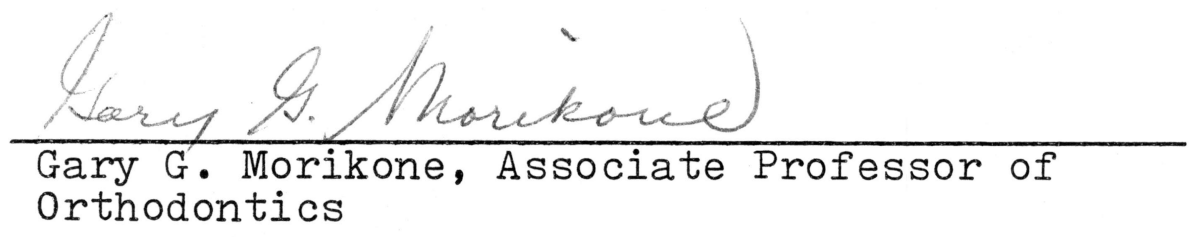


ACKNOWLEDGEVENTS

A manuscript is the culmination of the achievements of many contributors. It is with sincere appreciation and gratefulness that the author cites the individual efforts of the following people:

To the members of my research committee; Drs. J. Milford Anholm, Roland D. Walters, Lawrence W. Will, Willis I. Schlenker, Robert M. Ricketts, Lee E. Olsen, Gary G. Morikone for their guidance and suggestions.

To Gary Engel at Rocky Mountain Data Systems for his help in the statistical analysis and preparation of this manuscript.

To the staff at Rocky Mountain Data Systems, especially Iindy Harton who critiqued every tracing used in this study.

To Drs. Ruel W. Bench and Robert M. Ricketts for allowing the use of their patient records and offices, without which this study would not have been possible.

To the staff at the offices of Drs. Ruel W. Bench and Robert M. Ricketts for their help and patience in assisting me in finding the patient records that were used in this study .

To the Graphics Department at Loma Iinda University for their preparation of the graphs and figures used in this 
manuscript.

To Lucy Beck for her meticulous care in the typing of this manuscript.

To my twin brother Stan, whose inspiration kept me motivated during the trying times of my education.

And last, but certainly not least, to Cindy, whose great patience was there when I needed it most during the long hours while I wrote this manuscript.

Loma Iinda, California

May, 1981 
Maxillary expansion has been carried out for more than a century. This form of treatment has provoked great controversy within the orthodontic specialty. The prime objective of palatal expansion is to coordinate the maxillary and mandibular denture bases.

Expansion of narrow or collapsed maxillary arches has been performed in many different ways and may be achieved through tooth movement (orthodontic), orthopedic movement (bony), or a combination of the two. A wide range of appliances are used: fixed, semi-fixed and removable. There are many studies describing the clinical and cephalometric effects of rapid palatal expansion. 4, 6, 7, $11,12,16-19$ The objective of rapid palatal expansion is to produce maximum transverse separation of the maxilla while minimizing concomitant tooth movement within the bone. Since tooth movement can occur independently of the skeletal response, the theory has been that a rapid rate of bone separation has been considered essential. The rationale of rapid expansion therapy is to produce immediate bone repositioning while minimizing time for tooth movement.

However, dissenting opinions have been voiced in the orthodontic literature regarding the desirability and necessity of rapid expansion. 3, 9, 10 The slower expansion techniques have been associated with greater histologic 
integrity of the sutures as well as less relapse potential. $3,9,13,15$

Another aspect of palatal expansion is force magnitude. Historically, expansion appliance activation rates have been determined empirically. The applied force was developed from mechanisms of the jackscrew type with a high mechanical advantage and a high load-deflection rate. The attending clinical regimen has focused on the amount and frequency of mechanical adjustment. In a clinical study using a mechanical force-measuring dynamometer, Isaacson and Ingram ${ }^{10}$ quantitated force magnitude during rapid maxillary expansion. In their conclusions they called for the testing of slower activation schedules or expansion screws with less expansion per activation, and hypothesized that a constant acting force, with a low load-deflection rate, may be the most ideal. In a follow-up study on force levels during retention, $\mathrm{Zimring}$ and Isaacson $^{20}$ noted that the rate of load decay during fixed retention was essentially the same in all patients, regardless of the total load recorded at the end of the expansion period. They suggested that "the optimum rate of activation would be one whereby additional loads are added at close to the same rate that the facial skeleton can respond by physiological movement."

Fixed palatal arch appliances, such as the "Porter" or "W" appliance, are considered slow continuous force 
expansion devices and offer the advantages of minimal adverse effects on speech and removal of the adjustment responsibility from the patient. The "W" expansion appliance was originally used by Ricketts, et al. ${ }^{14}$ to treat cleft palate patierts. It was particularly advantageous because more movement could be gained in the anterior area than in the posterior area. Harberson and Myers, 8 using a "W" appliance in 10 patients with deciduous or mixed dentitions exhibiting posterior lingual cross-bites, showed radiographic evidence of the midpalatal suture opening in eight of the patients. Their conclusion was that the increase in maxillary widths of the eight patients was due to orthopedic movement of the maxillary halves. In order to widen the range of force application, to yield more flexibility and to enhance the ability to rotate molars, four helical loops were introduced and the quad-helix assumed its present day design (Fig. 1). Bell and LeCompte, ${ }^{1}$ using a quad-helix appliance on five deciduous and five mixed dentitions, each exhibiting a functional posterior cross-bite, demonstrated midpalatal sutural opening in all 10 subjects as evidenced by occlusal radiographs. The relative amounts of orthopedic and orthodontic changes were not evaluated. The purpose of this study is to examine the effects of maxillary quad-helix expansion on frontal and lateral cephalometric measurements in growing orthodontic patients. 
Methods and Materials

Twenty subjects, nine girls and eleven boys, each exhibiting at least a unilateral posterior lingual crossbite that was treated with a maxillary quad-helix appliance, were selected for inclusion in this study. The girls ranged in age from 7 years 2 months to 13 years 2 months, and the boys ranged in age from 7 years 2 months to 17 years 6 months. The mean starting age for all subjects was 10 years 3 months. The cases were chosen from two private orthodontic offices based on completeness of patient records.

The posterior-anterior and lateral cephalometric radiographs that were obtained prior to orthodontic treatment $\left(\mathrm{T}_{1}\right)$, after approximately six months of treatment ( $\mathrm{T}_{\text {prog }}$ ) and following completion of active orthodontic treatment or removal of orthodontic bands $\left(\mathrm{T}_{2}\right)$ were traced on tracing acetate by the principal investigator. The mean time from $\mathrm{T}_{1}$ to $\mathrm{T}_{\text {prog }}$ was nine months and from the $\mathrm{T}_{1}$ to $\mathrm{T}_{2}$ was 51 months.

As a supplement to the cephalometric radiographs, plaster dental casts were measured at $T_{1}$ and again at $T_{2}$. The cephalometric radiographs were evaluated at each of the three stages of therapy using the following measurements:

I. Lateral cephalograph--measured from tracings (Fig. 1) A. Angular measurements in degrees 
1. Palatal plane angle: the angle between Frankfort plane and the palatal plane

2. Maxillary depth: the angle between nasionbasion plane and nasion-A point plane

3. Maxillary height: the angle between nasion-CF line and $C F$-point A line

B. Linear measurements in millimeters

1. Convexity: the distance from point A to facial plane

C. VERT number: five lateral cephalometric measurements were compared to the Rocky Mountain Data Systems computer norms to determine how much each subject deviates from normal. The five measurements of the subject's whose clinical deviations are averaged include:

1. Mandibular plane angle: measured to Frankfort horizontal

2. Mandibular arc angle: the angle between the corpus and condyle axes

3. Facial axis: the angle between the facial axis and the basion-nasion plane 
4. Facial depth: the angle between the facial plane and Frankfort plane

5. Lower face height: the angle between a line from anterior nasal spine to the center of the ramus (" $X_{i}$ " point) and a line from pogonion to " $x_{i}$ " point

The average of the clinical deviations of the five measurements were used to establish a VERT number, or vertical description for each patient. If the VERT number is greater than, or equal to one, the patient is considered a brachyfacial person. If the VERT number is less than, or equal to -1 , the person is considered a dolicofacial person. If the VERT number is between 1 and -1 , the person is considered a mesofacial person.

II. Frontal cephalograph-measured from tracings (Fig. 3) A. Linear measurements in millimeters

1. Nasal width: the maximum width of the nasal cavity

2. Maxillary width: the distance between the right and left jugal processes (Bilateral points located at the intersection of the outline of the tuberosity and zygomatic buttress) 
3. Average Maxillo-mandibular width: the average of the left and right distances from the maxilla (jugal process) to the frontal facial plane on the respective side

4. Average Molar relation: the average of the distance between the buccal surface of the maxillary and mandibular first molars on the respective side, measured along the occlusal plane

5. Mandibular intermolar width: the distance between the left and right points $B 6$ and $6 B$, which are perpendicular projections of the buccal surfaces of the mandibular first permanent molars to the frontal occlusal plane

6. Maxillary intermolar width: the distance between the left and right points $A 6$ and $6 \mathrm{~A}$, which are perpendicular projections of the buccal surfaces of the maxillary first permanent molars to the frontal occlusal plane

7. Maxillary intercanine width: the distance between incisal tips of the maxillary canine

As a supplement to the cephalometric radiographs, the $\mathrm{T}_{1}$ and $\mathrm{T}_{2}$ dental casts were examined to measure the 
following effects:

1. Transverse change in maxillary intermolar width

2. Transverse change in mandibular intermolar width

Transverse measurements on the casts were made with a caliper with a sliding vernier scale (Boley gauge) to 0.1 $\mathrm{mm}$ by the principal investigator. The width was the distance measured between the buccal surfaces of the named teeth at the gingival margin with the arms of the caliper centered over the buccal grooves of the teeth being measured. It should be noted that sets of casts of only 18 out of the 20 patients were available for measurement.

Normal cranio-facial growth was used as a baseline for this study, as described by Dreskin, Schulhof and Bagha. 5 Both the $\mathrm{T}_{\text {prog }}$ and $\mathrm{T}_{2}$ tracings were corrected for growth by the computer and, in that way, the net effect of the quad-helix could be ascertained.

The first stage of data analysis was to describe the changes from $\mathrm{T}_{1}$ to $\mathrm{T}_{\text {prog, }} \mathrm{T}_{\text {prog }}$ to $\mathrm{T}_{2}$, and $\mathrm{T}_{1}$ to $\mathrm{T}_{2}$ in all variables mentioned above. The mean, standard deviation and Student's t tests were performed at the three time intervals to determine the amount of change, variability of the change, and significance of the changes respectively. The second stage of data analysis included three separate regression analyses. The purpose of the first 
multiple regression analysis was to create a method to predict skeletal changes as a result of quad-helix use prior to treatment. It was designed to correlate maxillary width increases from $\mathrm{T}_{1}$ to $\mathrm{T}_{\text {prog }}$ with values of all other variables at $\mathrm{T}_{1}$. The purpose of the second multiple regression analysis was to determine if the amount of maxillary molar expansion that held when $\mathrm{T}_{\text {prog }}$ and $\mathrm{T}_{2}$ time points were compared could be predicted at $\mathrm{T}_{1}$. It was designed to correlate percentage maxillary molar expansion that held from $\mathrm{T}_{\text {prog }}$ to $\mathrm{T}_{2}$ versus all variables at $\mathrm{T}_{1}$, and thereby predict stability. The purpose of the third multiple regression analysis was to determine if there was any relationship between a patient's facial description (VERT) at $\mathrm{T}_{1}$ and the amount of expansion observed from $\mathrm{T}_{1}$ to $\mathrm{T}_{\text {prog. }}$ Finally, composite frontal and lateral tracings at $\mathrm{T}_{1}, \mathrm{~T}_{\text {prog' }}$ and $\mathrm{T}_{2}$ were drawn by the computer (uncorrected for growth) to realize a comprehensive visual picture of growth and treatment combined, and to allow the ability to make successive superimpositions of the treatment intervals.

\section{Results}

The actual changes during each stage of therapy were compared with the normal growth changes that would occur in a statistically equivalent group. The normal changes are based on predictions from Rocky Mountain Data Systems. This study was concerned only with those changes 
that were significantly different from those that would occur as a result of normal growth.

The detailed significant findings were as follows:

I. $\mathrm{T}_{1}$ to $\mathrm{T}_{\text {prog' }}$ average time: 9 months (Table I)

A. Lateral examination

1. Maxillary height increased by an average of $.80^{\circ}$, which means the maxilla dropped downward since palatal plane showed no change.

2. Mandibular plane angle increased an average of $.61^{\circ}$ and facial axis opened an average of $.47^{\circ}$, indicating a slight bite opening due to the expansion therapy .

B. Frontal examination

1. Maxillary intermolar width increased an average of $5.88 \mathrm{~mm}$.

2. Maxillary intercanine width increased an average of $2.74 \mathrm{~mm}$.

3. Average molar relation increased an average of $2.95 \mathrm{~mm}$.

4. Maxillary width increased an average of $.92 \mathrm{~mm}$, with five out of the 20 cases showing increases of $2.7 \mathrm{~mm}$ or more. 
5. Average maxillo-mandibular width decreased an average of $.89 \mathrm{~mm}$ with four cases demonstrating decreases of $1.4 \mathrm{~mm}$ or more.

6. Nasal width increased an average of $.80 \mathrm{~mm}$.

II. $\mathrm{T}_{\text {prog }}$ to $\mathrm{T}_{2}$, average time: 42 months (Table II)

A. Lateral examination

1. Palatal plane decreased an average of $.66^{\circ}$, indicating the front of the palate dropped.

2. Maxillary depth decreased an average of $1.13^{\circ}$, possibly due to headgear wear since no attempt was made to omit subjects that used headgear.

3. Maxillary height increased an average of $.84^{\circ}$, and when considered with the palatal plane decrease, indicates no net parallel downward movement of the maxilla.

4. Facial depth decreased an average of $.56^{\circ}$, indicating a slight additional bite opening, possibly due to the normal orthodontic appliance therapy

5. Figure 4 is a summary illustration of the significant changes that took place in the various angular measurements. 
B. Frontal examination

1. Maxillary intercanine width increased an average of $4.05 \mathrm{~mm}$ due to eruption.

2. Maxillary width and average maxillo-mandibular width showed no significant changes from $\mathrm{T}_{\text {prog }}$ to $\mathrm{T}_{2} \cdot$

3. Insignificant relapse was observed in nasal width, average molar relation and maxillary intermolar width from $\mathrm{T}_{\text {prog }}$ to $\mathrm{T}_{2}$.

4. Figure 5 is a summary illustration of the changes that took place in the various linear measurements.

III. $\mathrm{T}_{1}$ to $\mathrm{T}_{2}$, average time: 51 months ( $\mathrm{Table}$ III)

A. Lateral examination

1. Palatal plane decreased an average of $.82^{\circ}$ and was significant at the $p=.01$ level.

2. Maxillary depth decreased an average of $1.44^{\circ}$ and this change was significant at the $p=.01$ level.

3. Maxillary height increased an average of $1.64^{\circ}$ and is significant at the $p=.05$ level. 
4. Facial axis opened an average of $1.03^{\circ}$ and was significant at the $p=.05$ level, probably due to the overall orthodontic therapy.

5. Mandibular plane angle increased an average of $1.06^{\circ}$ and was significant at the $p=.10$ level, again evidence of bite opening.

B. Frontal examination

1. The changes in maxillary intermolar width, maxillary intercanine width, average frontal molar relation and average maxillo-mandibular width, which were highly significant from $T_{1}$ to Tprog, all remained highly significant at the $p=.01$ level

2. A maxillary width increase of $1.17 \mathrm{~mm}$ was significant only at the $p=.05$ level, indicating relapse might have occurred in some cases.

3. Nasal width demonstrated no significant differences from growth.

C. Dental cast examination

1. An average maxillary intermolar increase of $5.02 \mathrm{~mm}$ was significant at the $p=.01$ level. 
2. No significant change for mandibular intermolar width was observed during treatment.

3. It should also be noted that no significant differences exist between the increase in maxillary intermolar width when the dental casts and the frontal cephalometric radiographs are compared. The casts show a mean increase of $5.02 \mathrm{~mm} \pm 1.69 \mathrm{~mm}$ from $\mathrm{T}_{1}$ to $\mathrm{T}_{2}$ and the radiographs show a mean increase of $5.16 \mathrm{~mm} \pm 1.94 \mathrm{~mm}$ from $\mathrm{T}_{1}$ to $\mathrm{T}_{2}$, both at the $\mathrm{p}=.01$ significance level. Therefore, the casts yielded no additional information over and above the cephalometric analysis.

Regression analyses. In the first multiple regression analysis, maxillary width increases from $\mathrm{T}_{1}$ to $\mathrm{T}_{\text {prog }}$ was the predicted variable. The variables, average molar relation at $\mathrm{T}_{1}$ and maxillary intercanine width at $\mathrm{T}_{1}$, were the independent variables and yielded a multiple correlation coefficient of $R=.72$. The interpretation of the result of this regression analysis is that the more orthopedic width increase observed during expansion, the more orthodontic expansion needed at the beginning of treatment.

When the second multiple correlation analysis was done, the percentage of maxillary molar expansion that held 
from $\mathrm{T}_{\text {prog }}$ to $\mathrm{T}_{2}$ was the dependent variable. The variables, nasal width at $\mathrm{T}_{1}$ and maxillary width at $\mathrm{T}_{1}$, were the independent variables and a multiple correlation coefficient of $R=.70$ was computed. Therefore, a narrow maxilla and a normal nasal width are the most favorable conditions for holding the achieved expansion and were the key variables in predicting expansion stability in this sample. Conversely, a wide maxilla and a narrow nasal width were found to be the least stable conditions in this study. In other words, better success is achieved by matching the narrow maxilla to the existing normal nasal width.

The third regression analysis was designed to determine if a subject's VERT at $\mathrm{T}_{1}$ is correlated with the amount of expansion. No statistically significant correlation was revealed between VERT and any variable measured in this study. Upon close examination, it was discovered that the random sample in this study was skewed to the brachyfacial side, thereby affecting the results of a regression analysis with VERT as the dependent variable.

Various other regression analyses were performed on the data of this sample, but were found to be insignificant. However, one variable that was important by virtue of its insignificance was that age was not found to be correlated with orthopedic or orthodontic expansion observed in the sample. 
Discussion

Up to this point, no known study has described the cephalometric changes as a result of maxillary quad-helix expansion. One purpose of this study was to delineate these changes and to ascertain if they were stable.

This study deals only with the average responses of maxillary quad-helix expansion and is intended to inform the clinician of the general trends and tendencies. Specific responses in individual cases must be carefully monitored and the design of treatment mechanics tailored during and after expansion to take advantage of the positive effects and combat the negative effects of expansion on each individual case.

The most dramatic orthodontic changes found in this

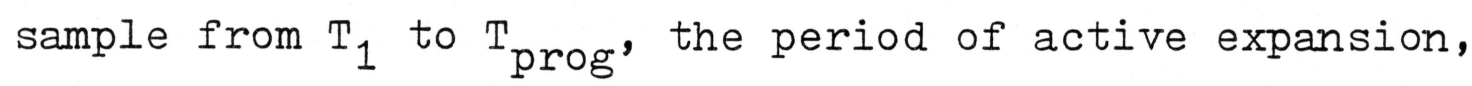
were a $5.88 \mathrm{~mm}$ mean increase in maxillary molar width, a $2.95 \mathrm{~mm}$ mean increase in average frontal molar relation, and a $2.74 \mathrm{~mm}$ mean increase in maxillary intercanine width.

The most significant orthopedic changes from $\mathrm{T}_{1}$ to $\mathrm{T}_{\text {prog }}$ were a $.92 \mathrm{~mm}$ increase in maxillary width, with five out of the 20 cases showing increases of $2.7 \mathrm{~mm}$ or more, and a $.89 \mathrm{~mm}$ increase in average maxillo-mandibular width, with four cases demonstrating increases of $1.4 \mathrm{~mm}$ or more. It can be concluded that moderate orthopedic expansion is definitely possible with the quad-helix as five cases in 
this sample of 20 cases demonstrate. However, only slight orthopedic changes were consistently demonstrated.

As an estimate of the rate of orthopedic to orthodontic movement from $\mathrm{T}_{1}$ to $\mathrm{T}_{\text {prog }}$ found in this study, one could divide the increase in maxillary width by the increase in maxillary intermolar width. If this is done an approximate ratio of $6: 1$ is obtained, indicating that for every millimeter of orthopedic or skeletal movement six millimeters of orthodontic tooth movement occurred.

The usual expansion regimen called for over-expansion to allow for relapse when the expansion appliance is removed. It is apparent then, that the dental relapse is expected for correction of the over-expanded teeth. However, the dental expansion was very stable over the average time of 42 months from $\mathrm{T}_{\text {prog }}$ to $\mathrm{T}_{2}$. Although the orthopedic effects with the quad-helix in this study are not as dramatic as with rapid palatal expansion, they are very stable and showed little relapse in this sample.

These results lend credence to the concept that slow expansion, that takes place at a rate to which the facial skeleton can respond to by physiological movement, is very stable and demonstrates less relapse potential than rapid expansion. Considering that 42 months elapsed between $T_{\text {prog }}$ to $\mathrm{T}_{2}$, sufficient time to evaluate relapse had elapsed. Therefore, this sample demonstrates that quad-helix expansion is stable with respect to time. 
The preceding analysis examined each stage of therapy separately. However, there are numerous possibilities for interaction among changes occurring at different stages. Therefore, ir a clinical study such as this, some parameters of the study could not be controlled. One such area would be the slight bite opening observed from $\mathrm{T}_{1}$ to

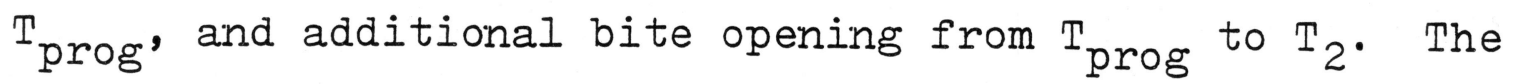
bite opening from $\mathrm{T}_{1}$ to $\mathrm{T}_{\text {prog }}$ is consistent with the reports in the literature of bite opening during expansion therapy due to occlusal interferences. 6, 7, 18, 19 However, the bite opening subsequent to expansion, $T_{\text {prog }}$ to $T_{2}$, is a feature of orthodontic treatment and can't be correlated with the expansion therapy, especially since the patients had the quad-helix removed at the time the progress films were taken.

The palate moved slightly downward during expansion

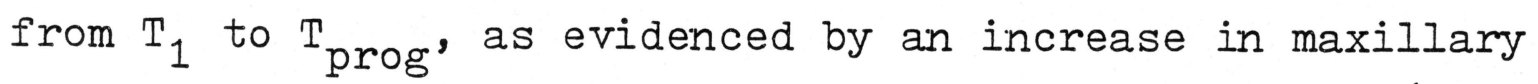
height, which is also consistent with the literature. 6, 7 , 18, 19 However, from $\mathrm{T}_{\text {prog }}$ to $\mathrm{T}_{2}$ maxillary height and palatal plane decreased, therefore, the net effect was a downward movement of A point only. That is to say, the palate tipped downward in the anterior but the posterior nasal spine remained essentially in the same place. As mentioned above, no attempt was made to omit subjects that used headgear as part of their orthodontic therapy. 
Figures 6,7 , and 8 are lateral computer composite tracings of the sample at $\mathrm{T}_{1}, \mathrm{~T}_{\text {prog }}$ and $\mathrm{T}_{2}$ respectively. Figures 9, 10, and 11 are frontal computer tracings at $T_{1}$, $\mathrm{T}_{\text {prog }}$ and $\mathrm{T}_{2}$ respectively. These composites are uncorrected for growth. It is sometimes very informative, especially for the clinician, if superimposition of tracings at the different time points of treatment are made to observe the effects of treatment, growth or a combination of the two. Figure 12 is a superimposition of the $T_{1}$ and $T_{\text {prog }}$ frontal tracings at the intersection of the frontal sagittal plane and occlusal plane. If the assumption is made that minimal growth took place in the time interval between the tracings, (average time was nine months) a reasonably accurate comprehensive cephalometric picture of the treatment effects of quad-helix expansion is realized. Besides the change in variables measured in this study and mentioned above, the significant eruption of the mandibular canines, as well as the very slight eruption of the maxillary canines, should be noted.

Figure 13 is the $\mathrm{T}_{\text {prog }}$ and $\mathrm{T}_{2}$ composite frontal tracing superimposed at frontal sagittal plane and occlusal plane to demonstrate the stability of the dental expansion, as well as the comprehensive dental changes of treatment and eruption.

Figure 14 is the $T_{1}$ and $T_{2}$ composite frontal tracings superimposed on the frontal sagittal and occlusal 
planes to show the comprehensive effects of dental expansion with the quad-helix appliance as well as dental eruption.

Figure 15 is the $\mathrm{T}_{1}$ and $\mathrm{T}_{2}$ composite frontal tracings superimposed on the frontal sagittal plane at the level of the jugal processes to demonstrate maxillary and nasal width increases resulting from treatment and growth.

Regression analyses. The fact that maxillary width increase from $T_{1}$ to $T_{2}$ was correlated $(R=.72)$ with $T_{1}$ maxillary intercanine width and $\mathrm{T}_{1}$ maxillary intermolar width is an intuitively logical statistical finding. It says, in effect, that the more dental expansion required at the beginning of treatment the greater orthopedic expansion realized during treatment. Apparently, the more net transverse expansion required for correction of the cross-bite, the longer the quad-helix was in place with a force applied and the longer the facial skeleton had to physiologically remodel and expand. Obviously, dental movement is occurring concomitantly with skeletal movement, and even to a greater degree, as the data in this study would indicate.

A much more interesting, but not immediately apparent, result appeared when the percentage maxillary molar expansion that held from $\mathrm{T}_{\text {prog }}$ to $\mathrm{T}_{2}$ was correlated with all of the variables at $\mathrm{T}_{1}$. The interesting result is that the percentage maxillary molar expansion that held was correlated $(R=.70)$ with the variables, maxillary width and 
nasal width, but with opposite polarities. That is to say, that the percentage expansion held was negatively correlated with maxillary width at $\mathrm{T}_{1}$ and positively correlated with nasal width at $\mathrm{T}_{1}$. Therefore, the most stable cases in this sample were those that demonstrated a narrow maxilla and a normal to wide nasal width at $\mathrm{T}_{1}$. Conversely, the least stable cases were those that began with a narrow nasal width and a normal maxillary width at $\mathrm{T}_{1}$.

Although this finding is not immediately apparent, it seems very logical. In a facial skeleton that begins with a narrow maxilla and a normal nasal width the environment can be made more favorable by increasing the maxillary width, and thereby obtaining stability. However, if the facial skeleton begins with a narrow nasal width and a normal maxilla (independent of the dental problem), an abnormal environment exists at the outset and any skeletal expansion only increases the degree of discrepancy and cannot be predicted to be as stable. Based upon this information, the clinical orthodontist should carefully examine the facial skeleton as found in a frontal cephalometric analysis when anticipating orthopedic expansion. The objective would be to create a more normal environment and not to create a more abnormal one. It would appear that the relationship between nasal width and maxillary width should be carefully considered when diagnosing and planning treatment for stable 
orthodontic results.

The random sample used in this study was skewed to the brachyfacial side; therefore, no correlation could be drawn between VERT and expansion variables measured in this study. This is unfortunate, otherwise an analysis could have been made to determine if any significant difference in expansion exists in the different facial types.

Limitations and future research. It would have been informative to have had a sample large enough, and of the right ages and facial types, to divide the subjects into mixed dentition, permanent dentition and facial type groups, to ascertain if any differences exist in orthopedic or orthodontic expansion between the groups. Also, no occlusal radiographs were taken during the active phase of expansion to check for mid-palatal sutural opening.

Therefore, there are good possibilities for future quad-helix studies by dividing the subjects into facial type and age groups. The sutural separation should also be studied by taking occlusal radiographs before and after the active expansion phase of treatment.

\section{Summary and Conclusions}

This study of the average response to maxillary expansion using the quad-helix appliance revealed the following significant results: 
1. The orthodontic changes included a mean increase in maxillary molar width of $5.88 \mathrm{~mm}$, a mean increase in average molar relation of $2.95 \mathrm{~mm}$, and a mean increase in maxillary intercanine width of $2.74 \mathrm{~mm}$. These increases were found to be stable through active treatment.

2. The orthopedic changes included a $.92 \mathrm{~mm}$ mean increase in maxillary width, which included five cases out of 20 that demonstrated an increase of $2.7 \mathrm{~mm}$ or more. Also, a $.89 \mathrm{~mm}$ mean increase in average maxillo-mandibular relation was observed, with four cases that demonstrated increases of $1.4 \mathrm{~mm}$ or more. These increases were stable throughout active treatment. It was concluded that moderate orthopedic expansion is possible with the quad-helix, but only slight orthopedic change was consistently demonstrated.

3. A 6:1 ratio of the amount of orthodontic movement to orthopedic movement was determined.

4. Nasal width showed no significant differences from growth during treatment.

5. No significant change in mandibular intermolar width was observed. 
6. A slight bite opening was observed on the lateral progress cephalograph during the expansion phase of treatment. A further bite opening was noted when the $\mathrm{T}_{1}-\mathrm{T}_{2}$ time interval was examined. The facial axis decrease was approximately $1^{\circ}$.

7. The most stable cases were those that presented with normal nasal widths and narrow maxillary widths.

8. The cases that demonstrated the most orthopedic changes during expansion were the same cases that required the greatest orthodontic changes at the beginning of treatment.

9. The amount of orthopedic and orthodontic changes observed did not correlate with the age of the patient.

10. The amount of orthopedic or orthodontic expansion did not correlate with the patient's facial type. This was thought to be due to the fact that this sample was skewed to the brachyfacial side. 


\section{REFERENCES}

1. Bell, R.A., and LeCompte, E. J.: The effects of maxillary expansion using a quad-helix appliance during the deciduous and mixed dentitions, Am. J. Orthod. 79: 152161,1981 .

2. Chaconas, S. J. and de Alba y Levy, J. A.: Orthopedic and orthodontic applications of the quad-helix appliance, Am. J. Orthod. 72: 422-428, 1977.

3. Cotton, I. A.: Slow maxillary expansion: Skeletal versus dental response to low magnitude force in Macaca mulatta, Am. J. Orthod. 73: 1-23, 1978.

4. Davis, W. M., and Kronman, J. H.: Anatomical changes induced by splitting of the midpalatal suture, Angle Orthod. 39: 126-132, 1969.

5. Dreskin, M., Schulhof, R., and Bagha, I.: A survey of standards for normal cranio-facial development, Proceedings--Foundation for Orthodontic Research, 126-227, 1976.

6. Haas, A. J.: Rapid expansion of the maxillary dental arch and nasal cavity by opening the midpalatal suture, Angle Orthod. 31: 73-90, 1961.

7. Haas, A. J.: The treatment of maxillary deficiency by opening the midpalatal suture, Angle Orthod. 35: 200217,1965 .

8. Harberson, V. A. and Myers, D. R.: Midpalatal suture opening during functional posterior cross-bite correction, Am. J. Orthod. 74: 310-313, 1978.

9. Hicks, E. P.: Slow maxillary expansion: A clinical study of the skeletal versus dental response to lowmagnitude force, Am. J. Orthod. 73: 121-141, 1978.

10. Isaacson, R. J., and Ingram, A. H.: Forces produced by rapid maxillary expansion II: Forces present during treatment, Angle Orthod. 34: 261-269, 1964.

11. Krebs, A. A.: Expansion of the midpalatal suture studied by means of metallic implants, Trans. Eur. Orthod. Soc. Rep. 34: 163-171, 1958. 
12. Krebs, A. A.: Midpalatal suture expansion studied by the implant method over a seven-year period, Trans. Eur. Orthod. Soc. pp 131-142, 1964.

13. Ohshima, 0.: Effects of lateral expansion force on the maxillary structure in the cynomolgus monkey, J. Osaka Dent. Univ. 6: 11-50, 1972.

14. Ricketts, R. M., Bench, R. W., Gungino, C. F., Hilgers, J. J. and Schulhof, R. J.: Bioprogressive Therapy, Rocky Mt. Orthod. 1: 255-258, 1979.

15. Storey, E.: Tissue response to the movement of bones, Am. J. Orthod. 64: 229-247, 1973.

16. Sugiyama, R. M.: Craniofacial changes resulting from expansion of the midpalatal suture in the Macaca mulatta monkey as revealed by roentgenographic analysis, Masters Thesis, Loma Linda University, 1968.

17. Walters, R. D.: Dimensional changes induced by forced separation of the midpalatal suture of the Macaca mulatta, Masters Thesis, Loma Linda University, 1967.

18. Wertz, R. A.: Skeletal and dental changes accompanying rapid midpalatal suture opening, Am. J. Orthod. 58: 4166,1970 .

19. Wertz, R. A., and Dreskin, M.: Midpalatal suture opening: a normative study, Am. J. Orthod. 71: 367-381, 1977 .

20. Zimring, J. E., and Isaacson, R. J.: Forces produced by rapid maxillary expansion III: Forces present during retention, Angle Orthod. 34: 178-186, 1965. 


\section{LIST OF TABLES}

TABLE

I. CEPHALOMETRIC CHANGES FROM $\mathrm{T}_{1}$ TO $\mathrm{T}_{\text {prog }}$ ( 9 MONTHS)

II. CEPHALONETRIC CHANGES FROM Tprog TO $\mathrm{T}_{2}$ ( 42 MONTHS)

III. CEPHALONETRIC CHANGES FROM $\mathrm{T}_{1}$ TO $\mathrm{T}_{2}$ (51 MONTHS) 


\section{TABLES}




\begin{tabular}{c|c|c|c}
\hline Measurement & $\begin{array}{c}\text { Mean } \\
\text { (mm/deg.) }\end{array}$ & $\begin{array}{c}\text { Standard } \\
\text { Deviation }\end{array}$ & $\begin{array}{c}\text { Significance } \\
\text { Level }\end{array}$ \\
\hline
\end{tabular}

I. Lateral Cephalograph

A. Angular measurements

$\begin{array}{lccr}\text { 1. Palatal plane } & -0.16 & 1.26 & \text { NS } \\ \text { 2. Maxillary depth } & -0.31 & 1.24 & \text { NS } \\ \text { 3. Maxillary height } & .80 & 1.79 & .10 \\ \text { 4. Mandibular plane } & .61 & 1.39 & .10 \\ \text { 5. Mandibular arc } & .34 & 2.35 & \text { NS } \\ \text { 6. Facial axis } & -.47 & 1.11 & .10 \\ \text { 7. Facial depth } & .11 & 1.17 & \text { NS } \\ \text { 8. Lower facial height } & .26 & 1.46 & \text { NS }\end{array}$

B. Linear measurements
1. Convexity
$-.04$
1.45
NS

II. Frontal Cephalograph

A. Linear measurements

1. Nasal width

.80

1.98

.10

2. Maxillary width

.92

1.59

.01

3. Average maxillo-mand. width

.89

1.01

.01

4. Average molar relation

2.95

1.74

.01

5. Mandibular intermolar width

.10

1.10

NS

6. Maxillary intermolar width

5.88

3.64

.01

7. Maxillary intercanine width

2.74

3.23

.01 


\begin{tabular}{l|c|c|c}
\hline Measurement & $\begin{array}{c}\text { Mean } \\
(\mathrm{mm} / \mathrm{deg} .)\end{array}$ & $\begin{array}{c}\text { Standard } \\
\text { Deviation }\end{array}$ & $\begin{array}{c}\text { Significance } \\
\text { Level }\end{array}$ \\
\hline
\end{tabular}

I. Lateral Cephalograph

A. Angular measurements

$\begin{array}{lccr}\text { 1. Palatal plane } & -0.66 & 1.57 & .10 \\ \text { 2. Maxillary depth } & -1.13 & 1.47 & .01 \\ \text { 3. Maxillary height } & 0.84 & 1.92 & .10 \\ \text { 4. Mandibular plane } & 0.45 & 1.89 & \text { NS } \\ \text { 5. Mandibular arc } & 0.94 & 2.74 & \text { NS } \\ \text { 6. Facial axis } & -0.56 & 1.47 & \text { NS } \\ \text { 7. Facial depth } & -0.56 & 1.12 & .05 \\ \text { 8. Lower facial height } & -0.20 & 1.52 & \text { NS }\end{array}$

B. Linear measurements

1. Convexity

$-0.68$

1.76

NS

II. Frontal Cephalograph

A. Linear measurements

1. Nasal width

$-0.44$

1.60

NS

2. Maxillary width

0.26

2.20

NS

3. Average maxillo-mand. width

0.30

1.22

NS

4. Average molar relation

$-0.25$

2.04

NS

5. Mandibular intermolar width

$-0.28$

2.10

NS

6. Maxillary intermolar width

$-0.72$

3.73

NS

7. Maxillary intercanine width

4.05

4.70

.01 


\begin{tabular}{c|c|c|c}
\hline Measurement & $\begin{array}{c}\text { Mean } \\
(\mathrm{mm} / \mathrm{deg} .)\end{array}$ & $\begin{array}{c}\text { Standard } \\
\text { Deviation }\end{array}$ & $\begin{array}{c}\text { Significance } \\
\text { Level }\end{array}$ \\
\hline
\end{tabular}

I. Lateral Cephalograph

A. Angular measurements

$\begin{array}{lccc}\text { 1. Palatal plane } & -0.82 & 1.52 & .01 \\ \text { 2. Maxillary depth } & -1.44 & 2.05 & .01 \\ \text { 3. Maxillary height } & 1.64 & 2.92 & .05 \\ \text { 4. Mandibular plane } & 1.06 & 2.51 & .10 \\ \text { 5. Mandibular arc } & 1.28 & 2.93 & .10 \\ \text { 6. Facial axis } & -1.03 & 1.98 & .05 \\ \text { 7. Facial depth } & -0.66 & 1.64 & .05 \\ \text { 8. Lower facial height } & 0.06 & 2.14 & .10\end{array}$

B. Linear measurements

1. Convexity

II. Frontal Cephalograph

A. Linear measurements

1. Nasal width

$\begin{array}{rrr}.36 & 1.85 & \text { NS } \\ 1.17 & 2.17 & .05 \\ 1.19 & 1.34 & .01 \\ 2.70 & 1.32 & .01 \\ -0.19 & 1.89 & \text { NS } \\ 5.16 & 1.94 & .01 \\ 6.79 & 3.64 & .01\end{array}$

2. Maxillary width

3. Average maxillo-mand. width

.01

4. Average molar relation

01

5. Mandibular intermolar width NS

6. Maxillary intermolar width

01

7. Maxillary intercanine width

01

III. Casts

1. Maxillary intermolar width

5.02

1.69

.01

2. Mandibular intermolar width

$.54 \quad 1.73$

NS 


\section{LIST OF FIGURES}

FIGURE

1. THE QUAD-HELIX APPLIANCE DEMONSTRATING THE ABILITY FOR IATERAL EXPANSION OF THE MAXILLARY BUCCAL SEGIVENTS AS WELI AS A ROTATION OF THE BANDED MOLAR.

2. LATERAI FILM TRACING SHOWING ANATOMICAI LANDMARKS AS WELI AS ANGULAR IINEAR MEASUREMENTS EMPLOYED.

3. FRONTAI FIIM TRACING SHOWING ANATOMICAL IANDMARKS AND LINEAR MEASUREMENTS EMPLOYED.

4. CHANGES IN ANGULAR MEASUREMENTS FROM $\mathrm{T}_{1}$ TO $\mathrm{T}_{\text {prog. }}$

5. CHANGES IN IINEAR MEASUREMENTS FROM $\mathrm{T}_{1}$ TO $\mathrm{T}_{\text {prog }}$

6. COMPOSITE LATERAI TRACING AT $\mathrm{T}_{1}$.

7. COMPOSITE LATERAL TRACING AT T $T_{\text {prog. }}$

8. COMPOSITE IATERAI TRACING AT T 2 •

9. COMPOSITE FRONTAL TRACING AT $\mathrm{T}_{1}$.

10. COMPOSITE FRONTAL TRACING AT Tprog.

11. COMPOSITE FRONTAL TRACING AT $\mathrm{T}_{2}$.

12. $\mathrm{T}_{1}$ AND $\mathrm{T}_{\text {prog }}$ COMPOSITE FRONTAL TRACINGS SUPERIMPOSED ON THE FRONTAL SAGITTAL AND OCCLUSAL PLANES.

13. $\mathrm{T}_{\text {prog }}$ AND $\mathrm{T}_{2}$ COMPOSITE FRONTAL TRACINGS SUPERINPOSED ON THE FRONTAL SAGITTAL AND OCCLUSAL PLANES.

14. $\mathrm{T}_{1}$ AND $\mathrm{T}_{2}$ COMPOSITE FRONTAL TRACINGS SUPERIMPOSED ON THE FRONTAI SAGITTAI AND OCCLUSAI PLANES.

15. $\mathrm{T}_{1}$ AND $\mathrm{T}_{2}$ COMPOSITE FRONTAL TRACINGS SUPERIMPOSED ON THE FRONTAL SAGITTAI PLANE AT THE LEVEL OF THE JUGAL PROCESSES. 
FIGURES 


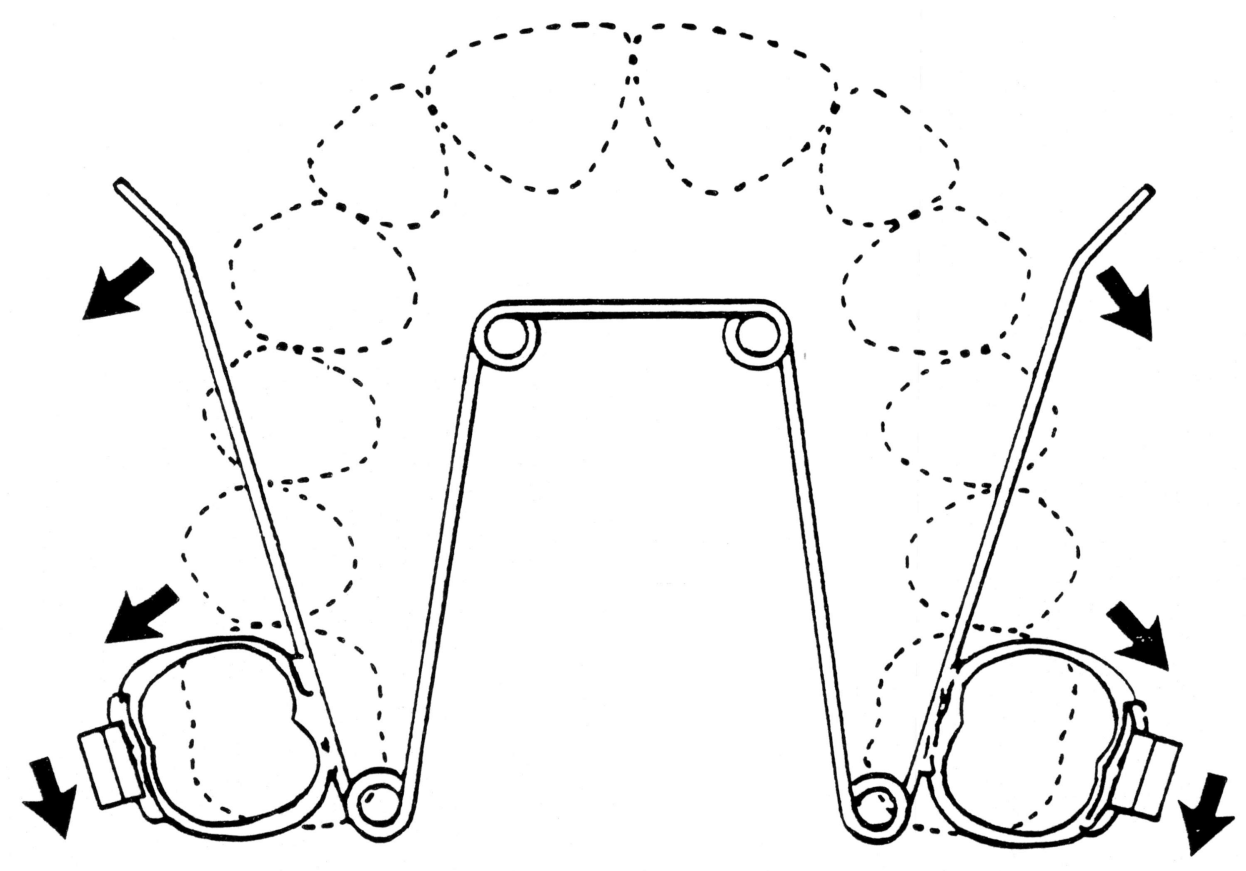

FIGURE 1 


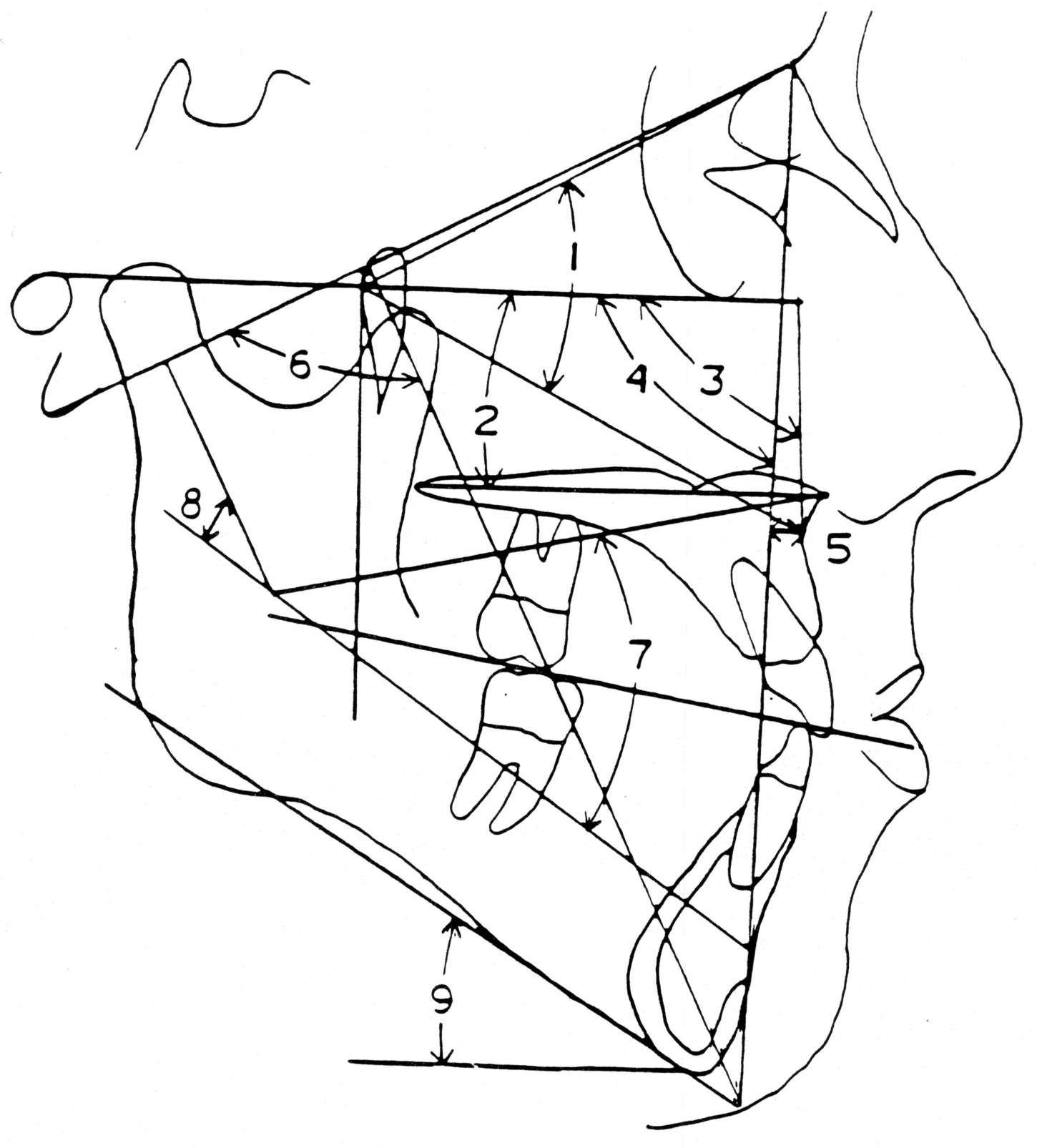

1. MAXILLARY HEIGHT

2. PALATAL PLANE

3. MAXILLARY DEPTH

4. FACIAL DEPTH

5. CONVEXITY 


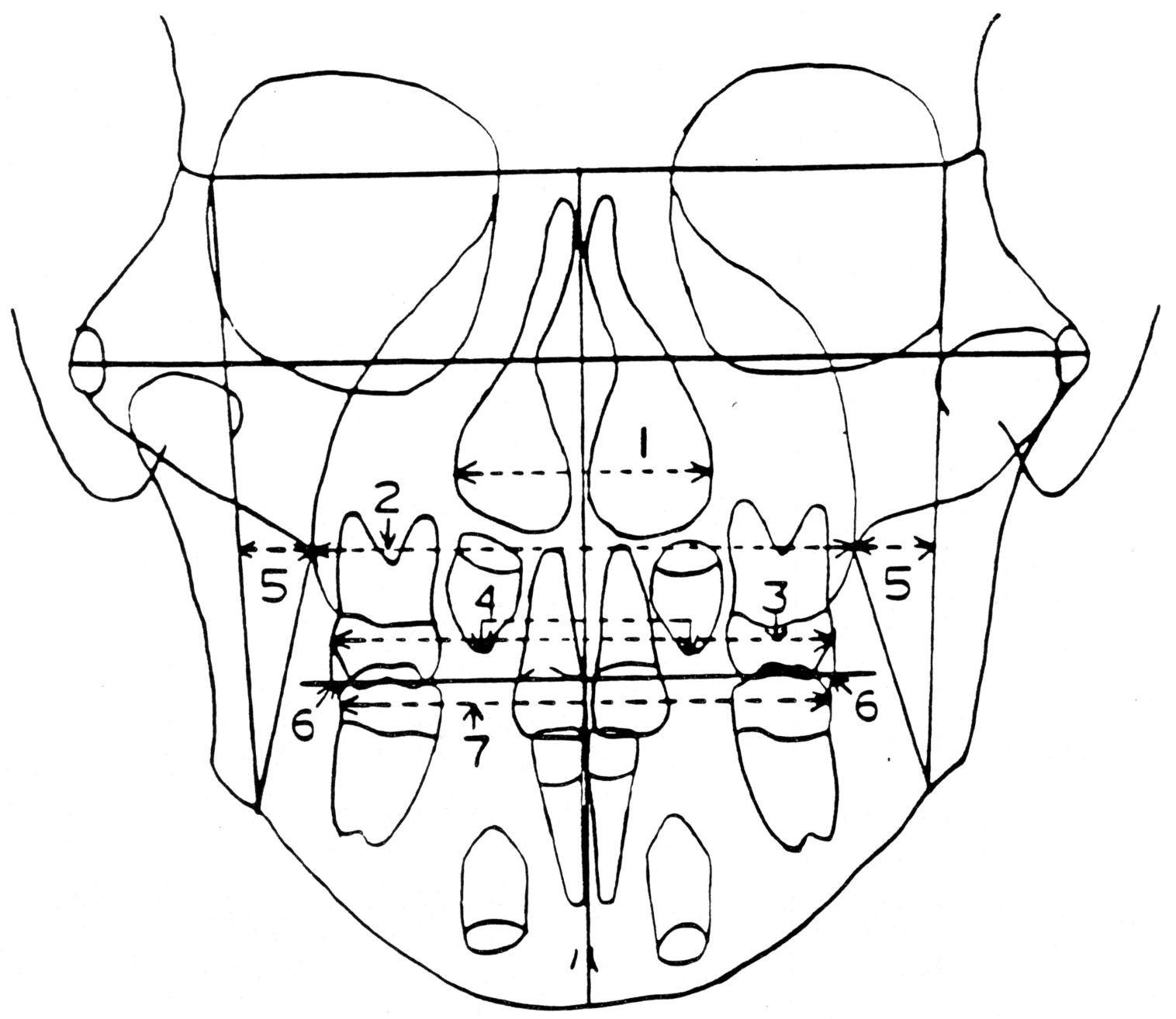

1. NASAL WIDTH

2. MAXILLARY WIDTH

3. MAXILLARY INTERMOLAR WIDTH

4. MAXILLARY INTERCANINE WIDTH

5. MAXILLO-MANDIBULAR WIDTH, LEFT AND RIGHT

6. MOLAR RELATION, LEFT AND RIGHT

7. MANDIBULAR INTERMOLAR WIDTH

FIGURE 3 
FACIAL AXIS*

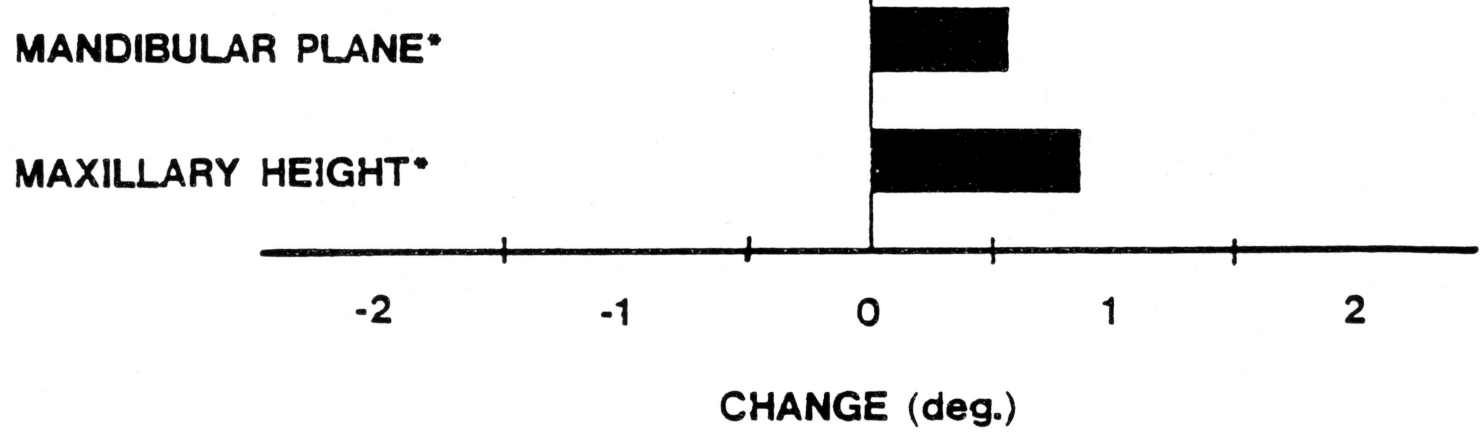

"significant at the $p=.10$ level

FIGURE 4 


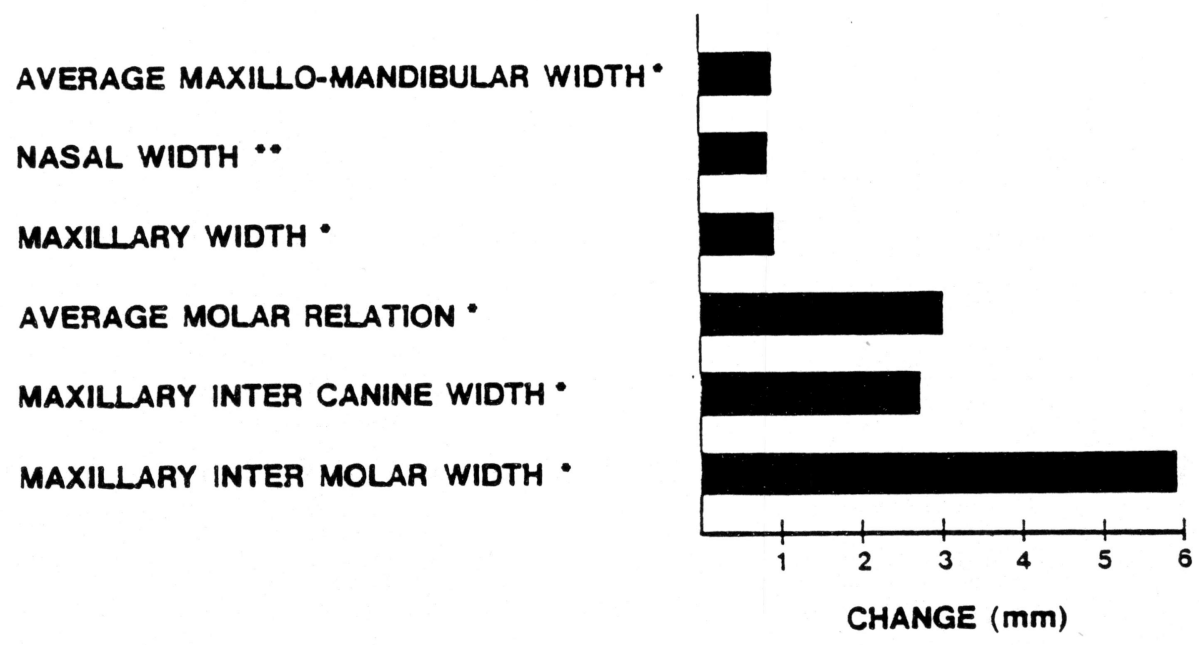

- Significant at the $P=.01$ Level

- - Significant at $P=0.1$ Level 


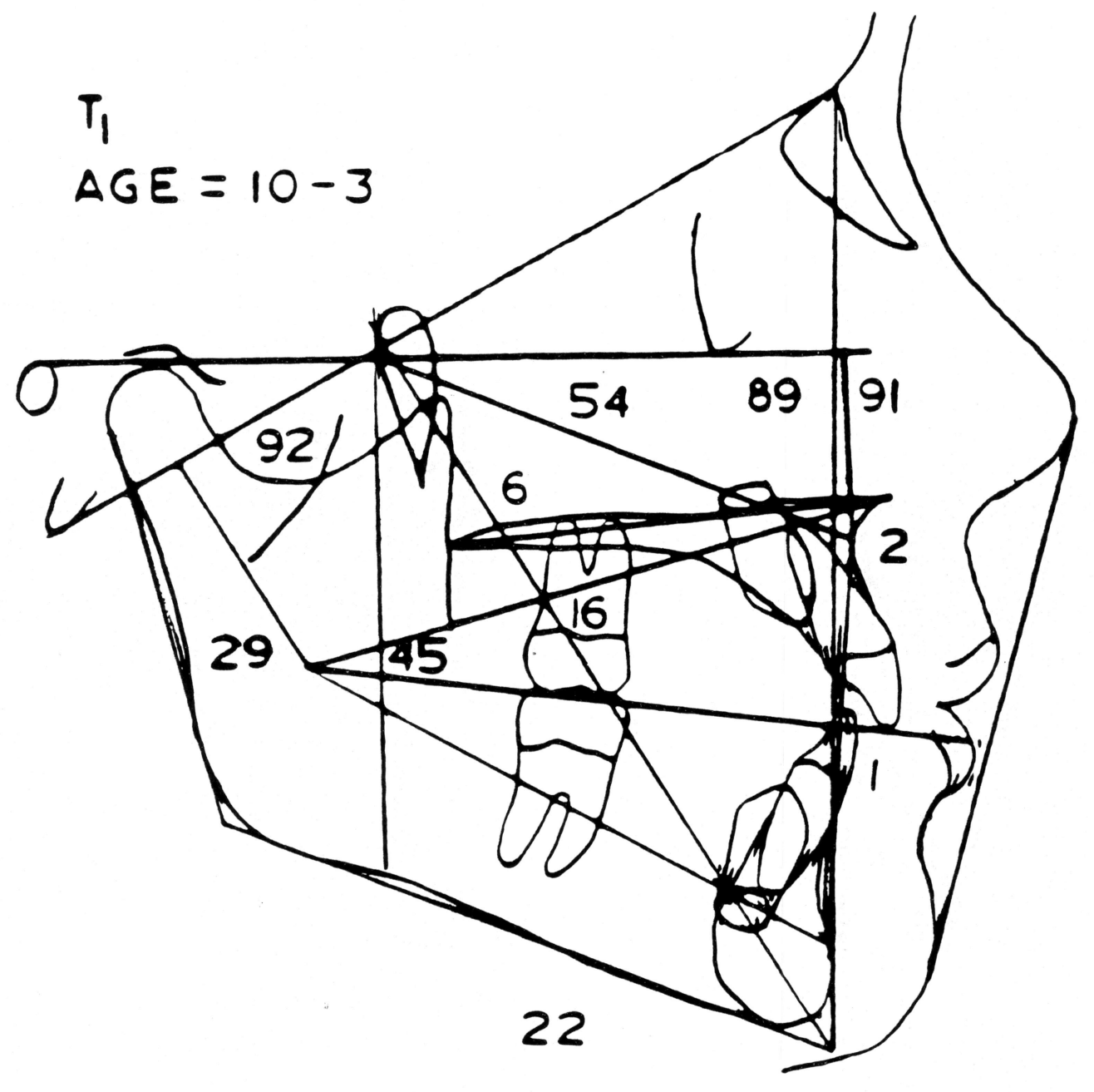

FIGURE 6 


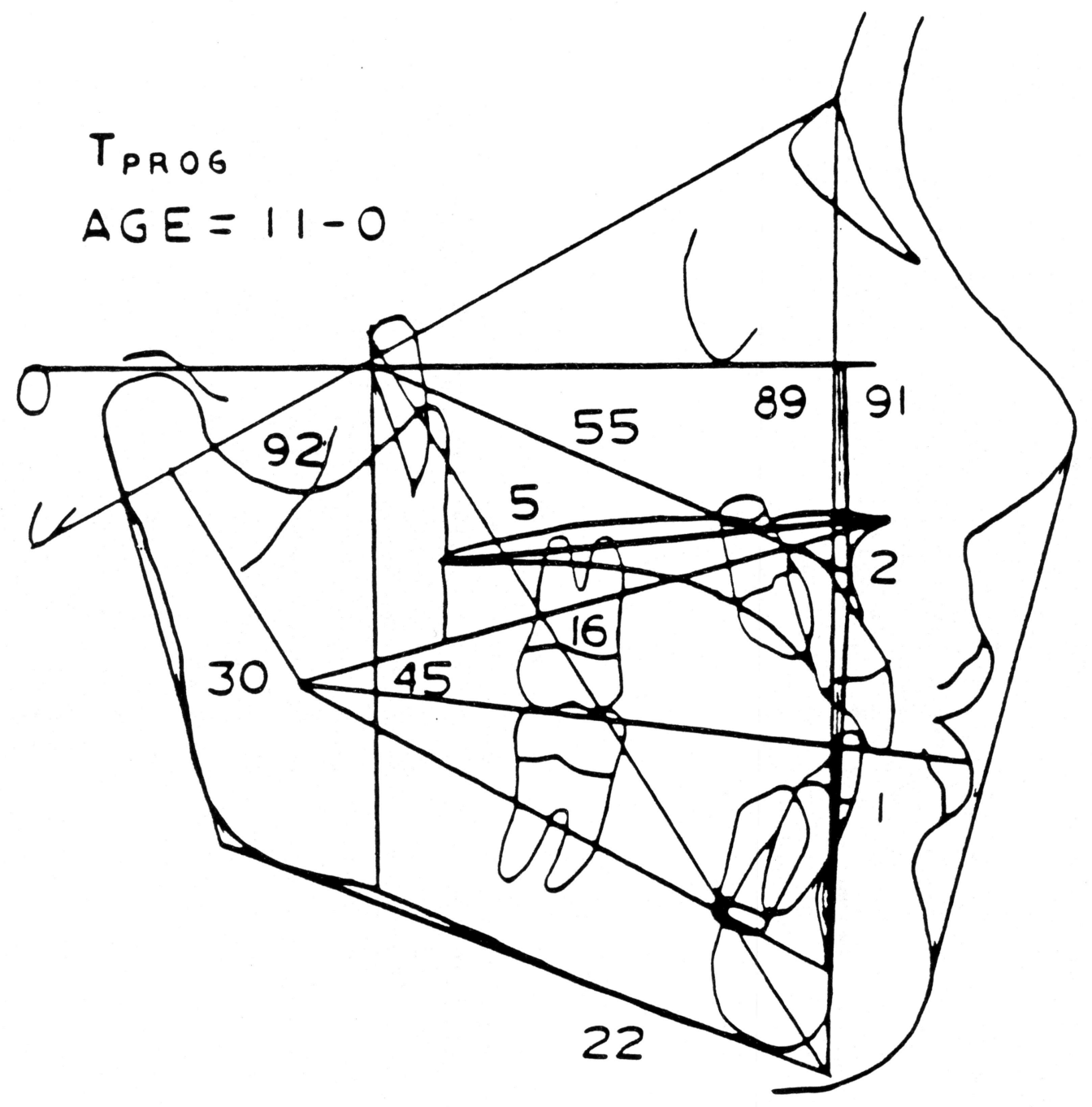

FIGURE 7 


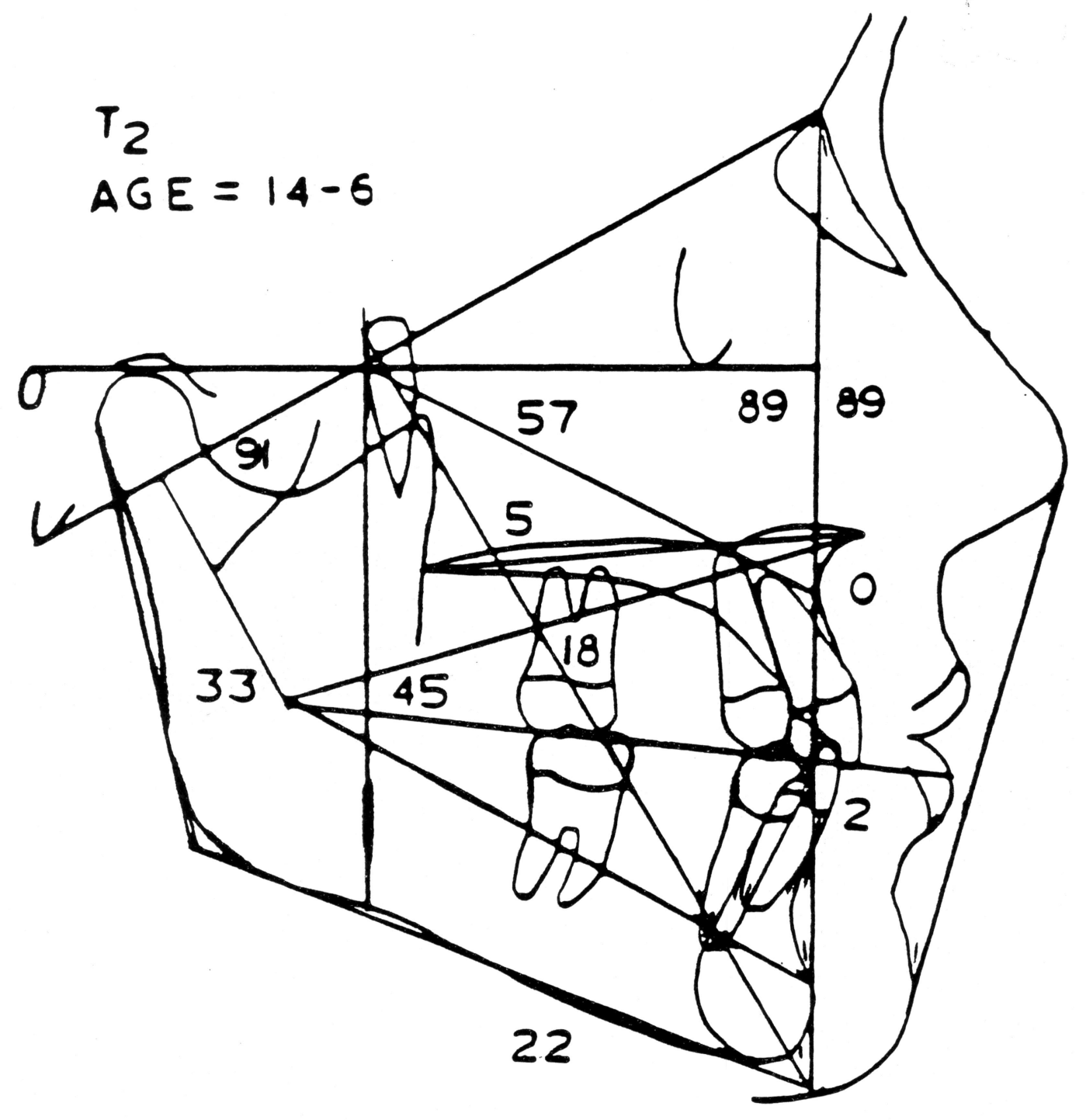

FIGURE 8 


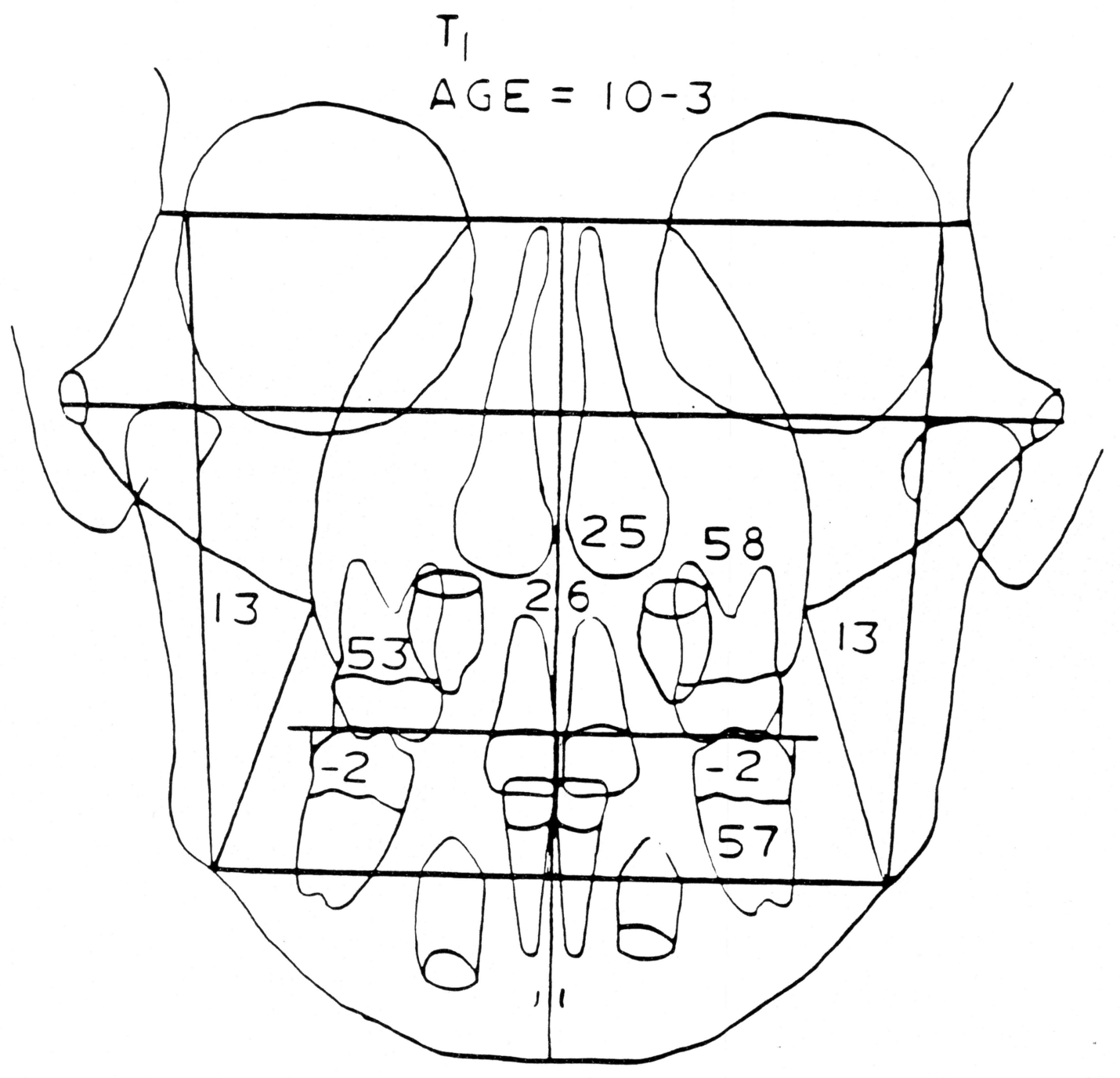

FIGURE 9 


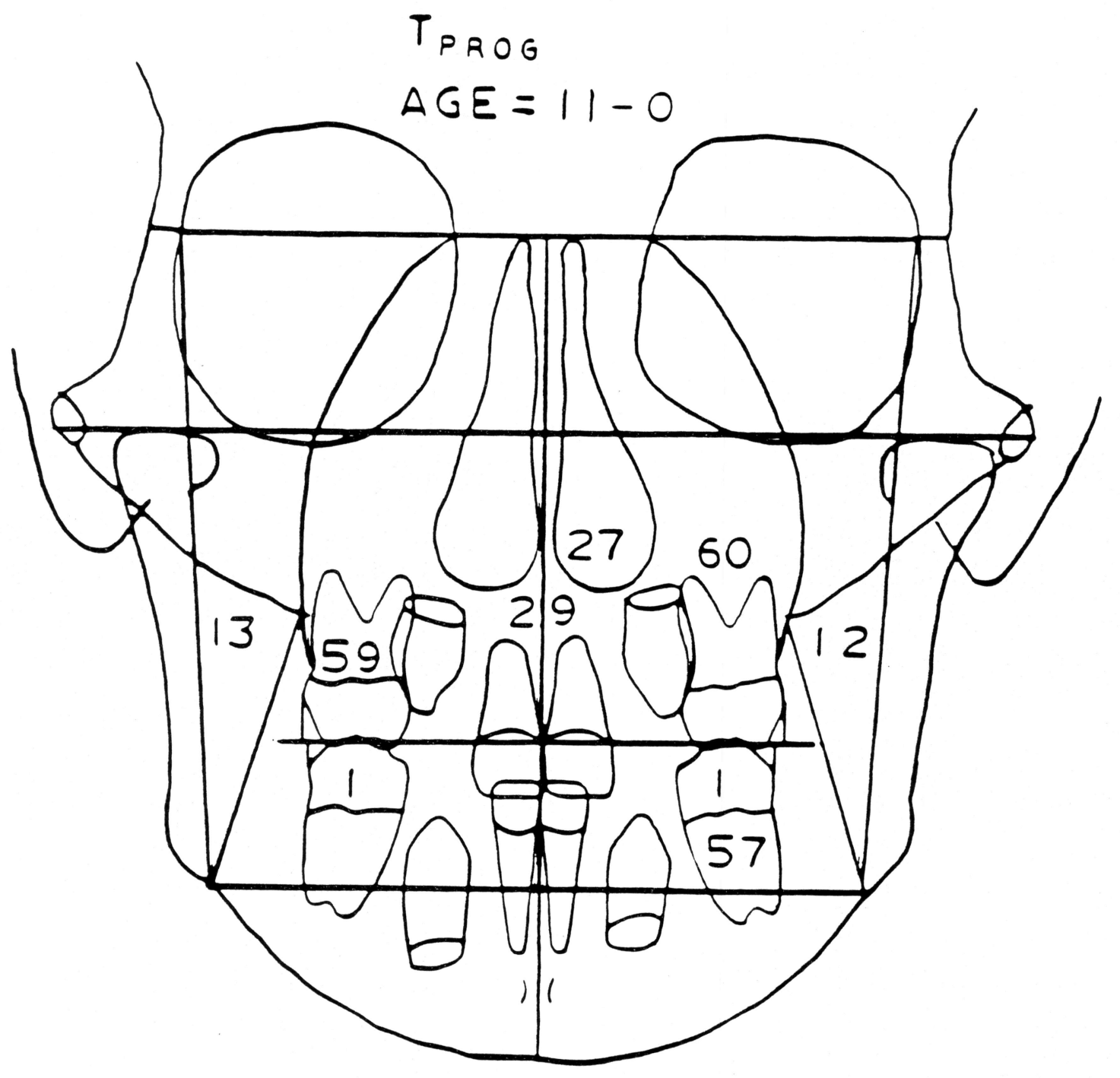

FIGURE 10 


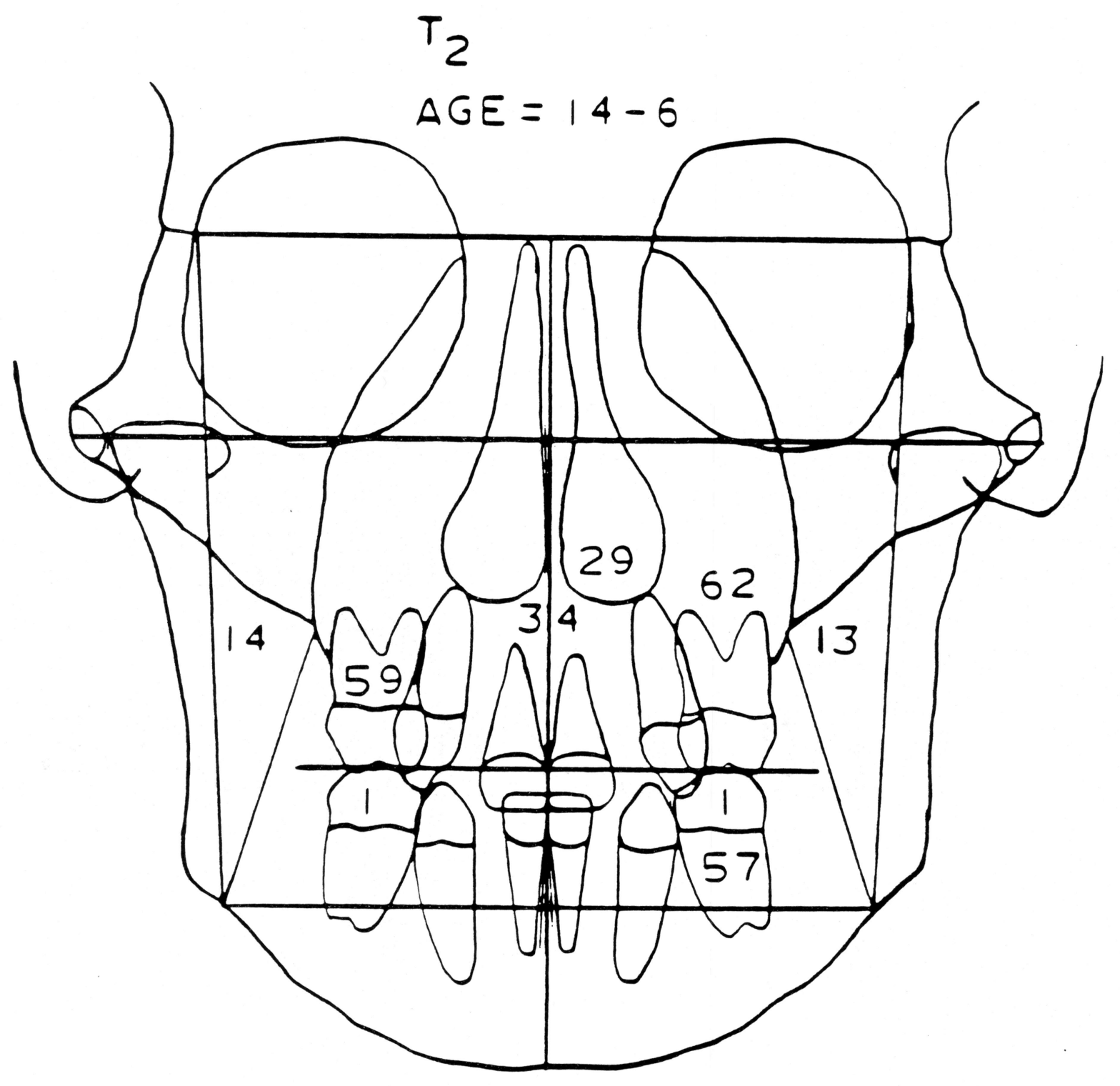

FIGURE 11 


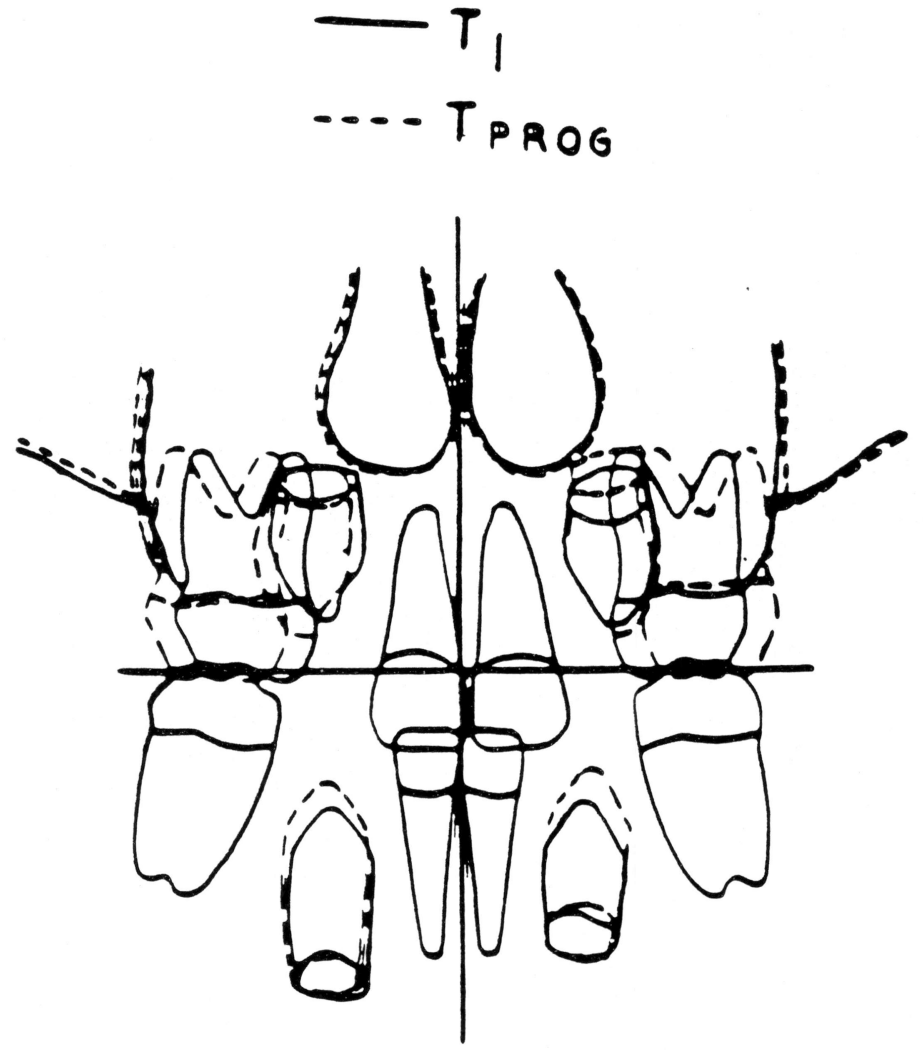

FIGURE 12 

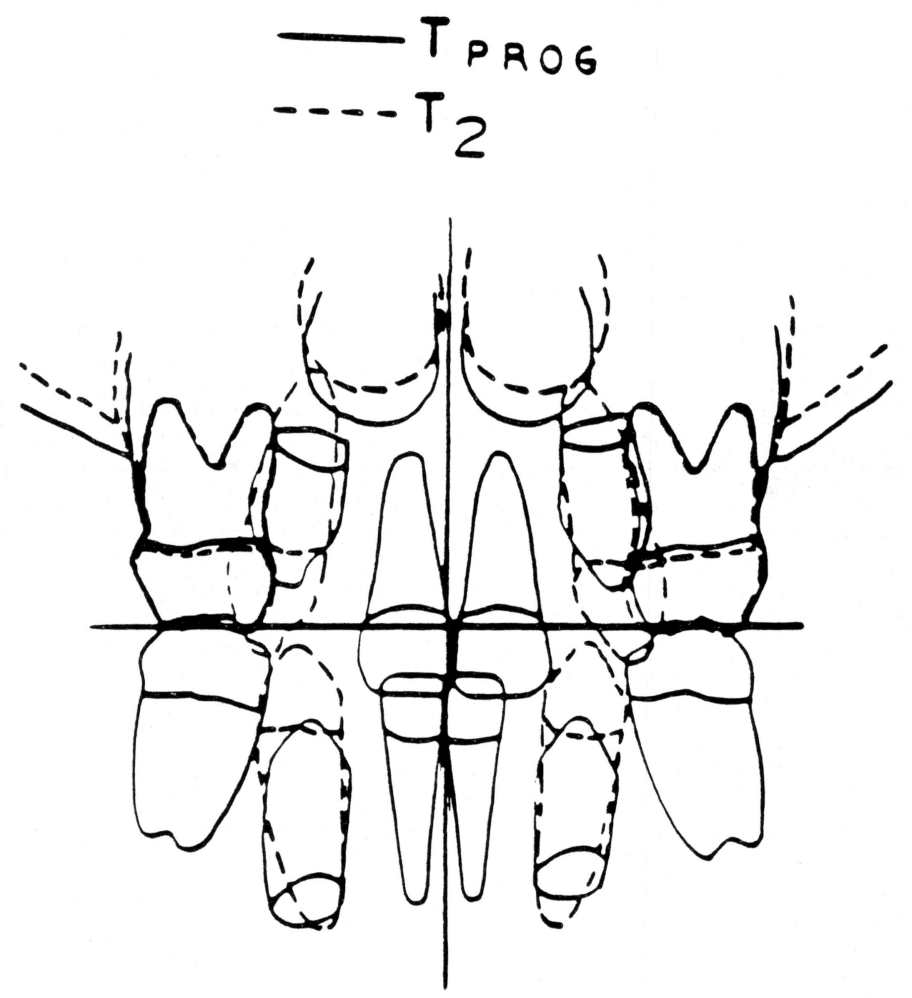

FIGURE 13 


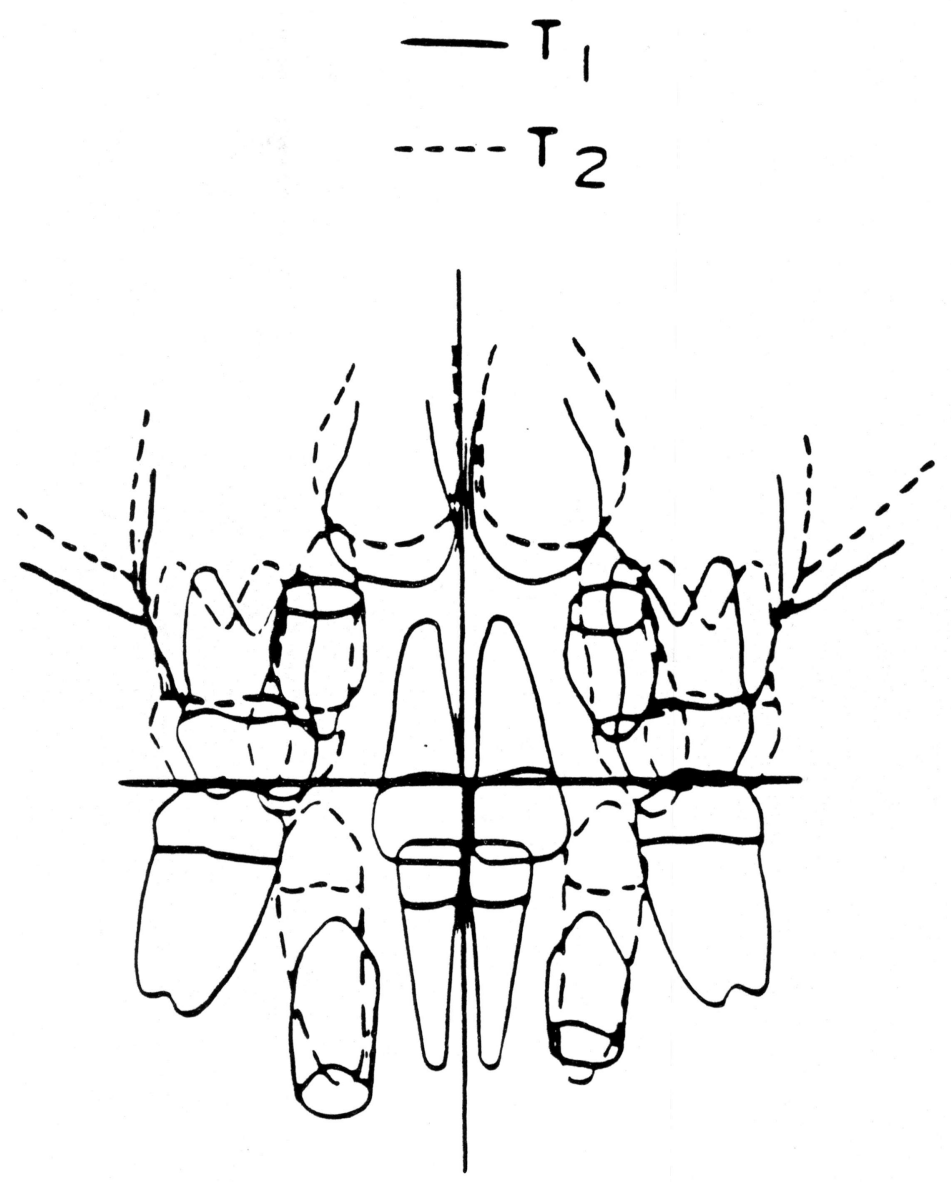

FIGURE 14 


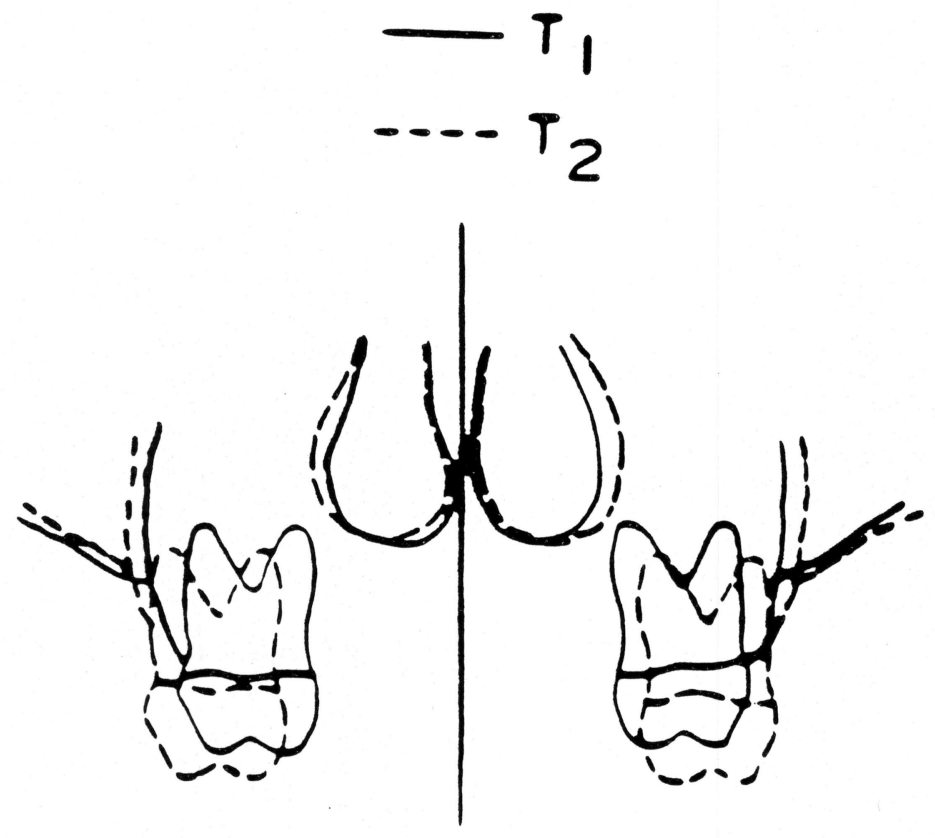

FIGURE 15 